\title{
SUBSTÂNCIAS ANTIMICROBIANAS PRODUZIDAS POR Bacillus spp. ISOLADOS DE FRUTAS
}

\author{
VINICYUS FORTES DE OLIVEIRA* \\ LUANA ROCHA FLEMING** \\ PATRÍCIA SILVIA FERREIRA*** \\ JANAIINA DOS SANTOS NASCIMENTO****
}

\begin{abstract}
O objetivo deste trabalho consistiu na investigação da produção de substâncias antimicrobianas por estirpes de Bacillus, isoladas de frutas, e verificar o potencial dessas substâncias na inibição de patógenos, associados à deterioração ou à transmissão de doenças por alimentos, como fungos e bactérias Gram-negativas ou Gram-positivas. Dez estirpes submetidas à coloração de Gram que mostraram ser bacilos foram testadas quanto à produção de substâncias antimicrobianas, utilizando-se como indicadoras diferentes bactérias Gram-positivas e Gram-negativas. Três estirpes, denominadas de Ame3, Mam1 e Pes1 apresentaram os maiores espectros de ação contra bactérias Gram-positivas, sugerindo que as substâncias produzidas por essas estirpes possam apresentar potencial de aplicação como biopreservativo de alimentos.
\end{abstract}

PALAVRAS-CHAVE: Bacillus sp.; BIOPRESERVATIVO DE ALIMENTOS; ANTIMICROBIANOS.

* Técnico em Alimentos pelo Instituto Federal do Rio de Janeiro (IFRJ), Graduando em Biologia, Universidade Federal do Rio de Janeiro (UFRJ), Rio de Janeiro, RJ (e-mail: vinicyusfortes@hotmail.com).

** Técnica em Biotecnologia pelo IFRJ, Graduanda em Medicina, UFRJ, Rio de Janeiro, RJ (e-mail:Ifleming@ hotmail.com).

*** Doutora em Microbiologia, Professora, IFRJ, Rio de Janeiro, RJ (e-mail: patricia.ferreira@ifrj.edu.br).

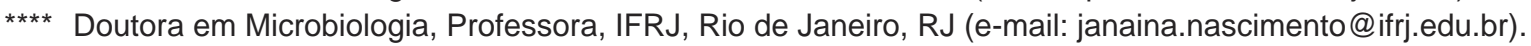




\section{INTRODUÇÃO}

Bactérias e fungos fazem parte da microbiota dominante de frutas e vegetais em geral (BEUCHAT, 1996), sendo que a maior parte dos contaminantes das frutas reside em sua parte externa. Seu interior permanece praticamente estéril a não ser que haja alguma ruptura de continuidade por lesões em alguma parte da casca (SANTOS, COELHO e CARREIRO, 2008). Esses microorganismos podem estar associados tanto à deterioração quanto à transmissão de doenças de origem alimentar, ocasionando perda econômica e problemas de saúde pública, respectivamente. $O$ Brasil, por exemplo, é o maior produtor mundial de frutas in natura. No entanto, esses produtos são altamente perecíveis e sofrem deterioração em poucos dias, o que dificulta a sua comercialização, especialmente para longas distâncias (BRUNINI, DURIGAN e OLIVEIRA, 2002; SANTOS, COELHO e CARREIRO, 2008).

Algumas bactérias patogênicas como, Salmonella, Listeria monocytogenes, Shigella, Escherichia coli e Bacillus cereus são de grande importância para a saúde pública e estão relacionadas com surtos de infecção alimentar em razão do consumo de frutas e hortaliças frescas contaminadas (BEUCHAT, 2002). Já os fungos assumem importância não somente sob o ponto de vista sensorial, devido à deterioração dos alimentos, mas também pelo perigo que a produção de micotoxinas representa para o consumidor (PEREIRA, CARVALHO e PRADO, 2002).

Tem sido observado aumento nos esforços para a pesquisa de novas substâncias que possam atuar não somente no tratamento, mas no controle e prevenção de doenças veiculadas por alimentos como frutas e hortaliças.

Os compostos biologicamente ativos produzidos por estirpes de Bacillus incluem alguns bem conhecidos como os antibióticos. Também se pode citar a butirosina, que é um aminoglicosídeo (SLEPECKY e HEMPHILL, 2006) e outra classe de substâncias: as bacteriocinas (SCHMITTER et al., 2007). Bacteriocinas constituem grupo de peptídios sintetizados via ribossomos e são, em geral, peptídios catiônicos de natureza hidrofóbica, cujo modo de ação principal está na formação de poros na membrana plasmática da célula alvo (McAULIFFE, ROSS e HILL, 2001; RISØEN et al., 2004).

Para a indústria de alimentos, a vantagem das bacteriocinas sobre os antibióticos reside no fato dessas serem degradadas por enzimas proteolíticas do sistema digestivo humano. Assim, podem ter aplicação na prevenção e controle de patógenos em alimentos, uma vez que antibióticos não podem ser utilizados em produtos alimentícios.

Algumas bacteriocinas produzidas por Bacillus sp são conhecidas como, por exemplo, a tochicina e as thuricinas 7 e 439, produzidas por B. thuringiensis (AHERN, VERSCHUEREN e VAN SINDEREN, 2003) e as cereínas de $B$. cereus (OSCÁRIZ, LASA e PISABARRO, 1999; BIZANI e BRANDELLI 2002). Essas bacteriocinas apresentam amplo espectro de ação contra diferentes bactérias Gram-positivas (RISØEN et al., 2004; OSCÁRIZ et al., 2005).

O objetivo deste trabalho consistiu na investigação da produção de substâncias antimicrobianas por estirpes de Bacillus, isoladas de frutas, e verificar o potencial dessas substâncias na inibição de patógenos, associados à deterioração ou à transmissão de doenças por alimentos, como fungos e bactérias Gram-negativas ou Gram-positivas.

\section{MATERIAL E MÉTODOS}

\subsection{OBTENÇÃO DAS AMOSTRAS}

As amostras de frutas (ameixa, banana, maçã, mamão e pêssego) foram adquiridas em mercados e feiras distribuídos em diferentes locais da cidade do Rio de Janeiro, sendo conduzidas imediatamente ao laboratório na embalagem fornecida pelo estabelecimento comercial.

\subsection{ISOLAMENTO E IDENTIFICAÇÃO DE BACTÉRIAS DO GÊNERO BACILLUS}

As frutas foram maceradas, assepticamente, e $10 \mathrm{~g}$ de cada amostra pré-enriquecidos em $90 \mathrm{~mL}$ de água peptonada $1 \%$ por 24 horas. Em seguida, a preparação foi aquecida a $80^{\circ} \mathrm{C}$ por 15 min, de modo a eliminar as bactérias não esporuladas. Alíquotas foram inoculadas através de "spread plate" em placas contendo ágar nutriente e incubadas à temperatura ambiente por $24 \mathrm{a}$ 
48 horas. As colônias suspeitas de Bacillus sp foram submetidas a coloração de Gram e de esporos. Os bacilos Gram-positivos esporulados foram repicados para ágar nutriente e identificados por meio de testes bioquímicos, conforme descrito por Clauss e Berkeley (1986).

\subsection{AVALIAÇÃO DA PRODUÇÃO DE SUBSTÂNCIAS INIBITÓRIAS POR ESTIRPES DE Bacillus}

Adotou-se o método descrito por Giambiagi-Demarval et al. (1990) e NASCIMENTO (2004), com algumas modificações. As estirpes se desenvolveram em placas contendo ágar tripticaseína de soja (TSA) a $37^{\circ} \mathrm{C}$ por $18 \mathrm{~h}$. Após a incubação, as culturas foram inoculadas sob a forma de pontos na superfície de placas contendo ágar TSA. Depois de $18 \mathrm{~h}$ a $37^{\circ} \mathrm{C}$, as bactérias foram mortas por exposição a vapores de clorofórmio por 30 min. Após sua evaporação, foram vertidos $3 \mathrm{~mL}$ de meio TSA semi-sólido acrescido de alíquotas de $0,3 \mathrm{~mL}$ da estirpe indicadora Micrococcus luteus (previamente crescida por $18 \mathrm{~h}$ a $37^{\circ} \mathrm{C}$, em $3 \mathrm{~mL}$ de caldo tripticaseína de soja - TSB). As placas foram reincubadas a $37^{\circ} \mathrm{C}$ por $18 \mathrm{~h}$, sendo a produção de substância inibitória indicada pelas zonas de inibição ao redor dos pontos de crescimento das estirpes produtoras.

\subsection{AVALIAÇÃO DO ESPECTRO DE AÇÃO DAS SUBSTÂNCIAS INIBITÓRIAS}

O espectro de ação foi determinado conforme descrito no item anterior, utilizando-se diferentes bactérias Gram-positivas e Gram-negativas. Os fungos filamentosos foram inoculados em placas de ágar TSA, juntamente com a estirpe produtora, verificando-se a inibição do crescimento fúngico (MACHADO et al., 2010).

\section{RESULTADOS E DISCUSSÃO}

Dez estirpes de bacilos Gram-positivos, isoladas de amostras de frutas, foram selecionadas para os estudos subsequentes (Tabela 1).

TABELA 1 - ESTIRPES DE Bacillus sp ISOLADAS DE FRUTAS

\begin{tabular}{cc}
\hline \hline Estirpes & Origem \\
\hline Ame1 & ameixa \\
Ame3 & ameixa \\
Ba4 & banana \\
3Ba1 & banana \\
3Ba5 & banana \\
Ma11 & banana \\
Mam1 & maçã \\
Mam2 & mamão \\
Pes1 & mamão \\
& pêssego \\
\hline
\end{tabular}

Todas as estirpes foram submetidas aos testes de produção de substâncias antagônicas, utilizando-se como indicadoras diferentes bactérias Gram-positivas e Gram-negativas. Das dez estirpes isoladas, oito (80\%) evidenciaram produção de algum tipo de substância antimicrobiana (Tabela 2). Nenhuma bactéria Gram-negativa testada foi inibida, entretanto, várias estirpes de Bacillus e Staphylococcus mostraram-se sensíveis às substâncias produzidas pela maior parte das estirpes. A Figura 1 mostra exemplo da inibição observada. As três estirpes de Bacillus que apresentaram 
o melhor espectro de ação foram identificadas como Bacillus pasteurii (Pes1) e Bacillus insolitus (Mam2 e Ame3).

\section{TABELA 2 - INIBIÇÃO DE BACTÉRIAS PELAS ESTIRPES DE Bacillus sp ISOLADAS NESTE TRABALHO}

\section{Produtoras}

\begin{tabular}{|c|c|c|c|c|c|c|c|c|}
\hline Indicadoras & Ame1 & 3Ba2 & 3Ba1 & Ame3 & Mam1 & Mam2 & Pes1 & 3Ba5 \\
\hline Ame1 & - & - & - & - & - & - & + & - \\
\hline Ame3 & _ & _ & _ & _ & _ & _ & + & _ \\
\hline 3Ba1 & - & - & - & + & - & - & + & + \\
\hline 3Ва5 & - & - & - & - & - & - & + & - \\
\hline Mam2 & - & - & - & - & - & - & + & - \\
\hline Bacillus cereus LMIFRJ & + & + & - & + & - & + & + & - \\
\hline Bacillus circulans LMIFRJ & - & - & + & + & + & + & - & - \\
\hline Bacillus megaterium LMIFRJ & _ & _ & _ & + & _ & + & - & _ \\
\hline Bacillus stearothermophilus NCTC 10339 & + & - & - & + & - & + & + & - \\
\hline Bacillus thuringiensis LMIFRJ & - & - & - & + & - & + & + & - \\
\hline Micrococcus luteus LMIFRJ & + & + & - & - & - & + & + & - \\
\hline Staphylococcus epidermidis ATCC 14990 & - & - & - & + & - & + & + & - \\
\hline Staphylococcus epidermidis ATCC 35984 & - & - & - & + & - & + & - & - \\
\hline Staphylococcus aureus ATCC 12600 & - & - & - & + & - & + & + & - \\
\hline
\end{tabular}

+, inibição; -, ausência de inibição; LMIFRJ, Laboratório de Microbiologia do IFRJ. Apenas as estirpes que foram inibidas por pelo menos uma produtora estão apresentadas nessa tabela. As estirpes Gram-positivas Staphylococcus aureus 33591, Staphylococcus aureus 29213, Bacillus thuringiensis ATCC 33679 e Bacillus subtilis ATCC 6633, assim como as Gram-negativas Acinetobacter bawanii ATCC 19604, Escherichia coli ATC 25922, Klebsiella pneumoniae ATCC 4352, Pseudomonas aeruginosa ATCC 27853, Pseudomonas fluorescens ATCC13525, Salmonella enterica subsp. enterica sorotipo Typhi ATCC 19214 e Yersinia enterocolitica ATCC 9610 não foram inibidas por nenhuma das produtoras testadas.

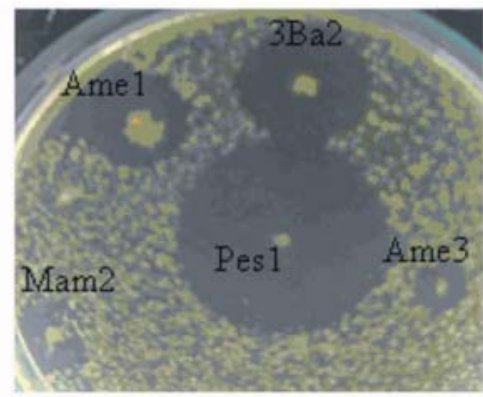

\section{FIGURA 1 - TESTE DE PRODUÇÃO DE SUBSTÂNCIAS ANTIMICROBIANAS, SENDO M. luteus, A ESTIRPE INDICADORA}

A contribuição mais conhecida do gênero Bacillus para a indústria de alimentos reside na produção de grande variedade de enzimas, tais como fitase, xilanase, ciclodextrinase, queratinase e amilase (SCHULZ, BONELLI e BATISTA, 2005). Entretanto, como verificado neste trabalho, esse gênero pode produzir substâncias antimicrobianas que são ativas contra microorganismos envolvidos em deterioração e toxinfecções alimentares, como é o caso de Bacillus cereus, patógeno clássico associado à síndrome diarréica ou emética (JAY, 2000).

Uma vez que a estirpe Pes1 apresentou o melhor espectro de ação assim como os maiores halos de inibição, a mesma foi escolhida para o teste de atividade contra fungos filamentosos e mostrou-se capaz de inibir Aspergillus niger (Figura 2) e Aspergillus flavus. 


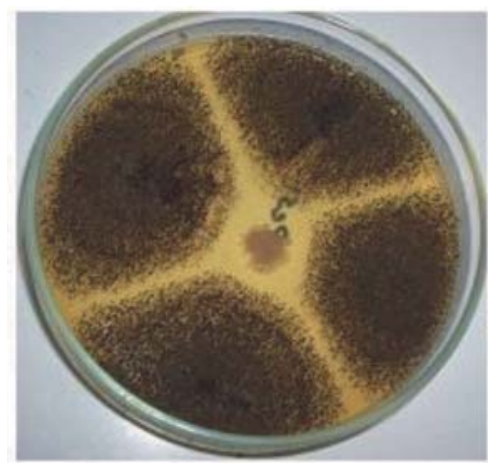

\section{FIGURA 2 - TESTE DE PRODUÇÃO DE SUBSTÂNCIAS ANTAGÔNICAS, SENDO A. niger A ESTIRPE INDICADORA E PES1 A ESTIRPE PRODUTORA}

Nota: Mesmo após duas semanas de incubação, o fungo não foi capaz de crescer ao redor da estirpe produtora.

\section{CONCLUSÃO}

Três das estirpes isoladas de frutas, Pes1, Ame3 e Mam2 apresentaram maior potencial para inibição de bactérias Gram-positivas, sugerindo que as substâncias produzidas por essas estirpes possam apresentar aplicação e constituir nova alternativa para indústria na área de conservação de alimentos, seja como agentes antibacterianos, ou como agentes antifúngicos.

Novos testes serão realizados com maior número de bactérias Gram-positivas e Gramnegativas, assim como de fungos filamentosos. A natureza bioquímica das substâncias detectadas neste trabalho também está sendo estudada, visando determinar se as mesmas são proteicas, sugerindo então que possam ser bacteriocinas.

\section{ABSTRACT}

\section{ANTIMICROBIAL SUBSTANCES PRODUCED BY Bacillus spp. ISOLATED FROM FRUITS}

The present work aimed to investigate the production of a new antimicrobial substances by Bacillus $s p$. isolated from fruit, and verify its potential as a pathogen inhibitor associated to deterioration and food disease transmission, such as fungus and Gram-positive and Gram-negative bacteria. Ten strains were submitted to Gram stain and showed to be bacilli. These strains were tested for production of antimicrobial substances, using as indicators different Gram-positive bacteria. Three strains, named Ame3, Mam1 and Pes1 presented the largest spectrum of action against Gram-positive bacteria, suggesting that the substances produced by these strains may have some potential application as food biopreservative.

KEY-WORDS: Bacillus sp.; FOOD BIOPRESERVATIVE; ANTIMICROBIAL SUBSTANCES.

\section{REFERÊNCIAS}

1 AHERN, M.; VERSCHUEREN, S.; VAN SINDEREN, D. Isolation and characterization of a novel bacteriocin produced by Bacillus thuringiensis strain B439. FEMS Microbiology Letters, v. 220, p.127-131, 2003.

2 BEUCHAT, L. R. Pathogenic microorganisms associated to fresh product. Journal of Food Protection, v. 59, p. 204-216, 1996.

3 BEUCHAT, L. R. Ecological factor influencing survival and growth of humans pathogens on raw fruits and vegetables. Microbes and Infections, v. 4, p. 413-423, 2002. 
4 BIZANI, D.; BRANDELLI, A. Characterization of a bacteriocin produced by a newly isolated Bacillus sp. strain 8A. Journal of Applied Microbiology, v. 93, p. 512-519, 2002.

5 BRUNINI, M. A.; DURIGAN, J. F.; OLIVEIRA, A. L. Avaliação das alterações em polpa de manga "Tommy-Atkins" congeladas. Revista Brasileira de Fruticultura, v. 24, n. 3, p. 651-653, 2002.

6 CLAUSS, D.; BERKELEY, R. C. W. Genus Bacillus Cohn 1872. In: BERGEY'S manual of determinative bacteriology. Baltimore, MD: Williams \& Wilkins, 1986. p. 1105-1141.

7 GIAMBIAGI-DEMARVAL, M.; MAFRA, M. A.; PENIDO, E. G. C.; BASTOS, M. C. F. Distinct groups of plasmids correlated with bacteriocin production in Staphylococcus aureus. Journal of General Microbiology, v.136, p.1591-1599, 1990.

8 JAY, J. M. Modern food microbiology. $6^{\text {th }}$ ed. London: Aspen Publ., 2000. $620 p$

9 MACHADO, A. P.; VIVI, V. K.; TAVARES, J. R.; GUEIROS FILHO, F. J.; FISCHMAN, O. Antibiosis and dark-pigments secretion by the phytopathogenic and environmental fungal species after interaction in vitro with a Bacillus subtilis isolate. Brazilian Archives of Biology and Technology, v. 53, p. 997-1004, 2010.

10 McAULIFFE, O.; ROSS, R. P.; HILL, C. Lantibiotics: structure, biosynthesis and mode of action. FEMS Microbiology Reviews, v. 25, p. 285-308, 2001.

11 NASCIMENTO, J. S. Produção de bacteriocinas por estirpes de Staphylococcus coagulase-negativos associados à mastite bovina e estudo do papel da orf12, orf13 e orf14 na expressão da aureocina A53. 2004.198 p. Tese (Doutorado em Microbiologia), Instituto de Microbiologia, Universidade Federal do Rio de Janeiro, Rio de Janeiro, 2004.

12 OSCÁRIZ, J. C.; LASA, I.; PISABARRO, A. G. Detection and characterization of cerein 7, a new bacteriocin produced by Bacillus cereus with a broad spectrum of activity. FEMS Microbiology Letters, v. 178, p. 337-341, 1999.

13 OSCÁRIZ, J. C.; CINTAS, L.; HOLO, H.; ÍLASA, I.; NES, I. F.; PISABARRO, A. G. Purification and sequencing of cerein 7B, a novel bacteriocin produced by Bacillus cereus Bc7. FEMS Microbiology Letters, v. 254, n. 1, p. $108-115,2005$.

14 PEREIRA, M. M. G.; CARVALHO, E. P.; PRADO, G. Crescimento e produção de aflatoxinas por Aspergillus flavus e Aspergillus parasiticus. Boletim do CEPPA, v. 20, n. 1, p. 141-156, jan./jun. 2002.

15 RIS $\varnothing E N$, P. A.; RØNNING, P.; HEGNA, I. K.; KOLST $\varnothing$, A. B. Characterization of a broad range antimicrobial substance from Bacillus cereus. Journal of Applied Microbiology, v. 96, p. 648-655, 2004.

16 SANTOS, C. A. A.; COELHO, A. F. S.; CARREIRO, S. C. Avaliação microbiológica de polpas de frutas congeladas. Ciência e Tecnologia de Alimentos, v. 28, n. 4, p. 913-915, 2008.

17 SCHMITTER, J.M.; BRESSOLLIER, P.; VERNEUIL, B.; CHOBELET, A.; BALLADE, A.; URDACI, M. Search for new antibiotics produced by Bacillus strains. In: ASMS CONFERENCE, 55., 2007. Proceedings ... Santa Fé: American Society for Mass Spectrometry, 2007. Supplement 5.

18 SCHULZ, D.; BONELLI, R. R.; BATISTA, C. R. V. Bacteriocinas e enzimas produzidas por Bacillus spp. para conservação e processamento de alimentos. Alimentos e Nutrição (Araraquara), v. 16, n. 4, p. 403-411, 2005.

19 SLEPECKY, R. A.; HEMPHILL, H. E. The Genus Bacillus - nonmedical. In: THE PROKARYOTES. $3^{\text {rd }}$ ed. New York: Springer, 2006. v. 4, p. 530-562. 